\title{
KDR Intron 2 VNTR
}

National Cancer Institute

\section{Source}

National Cancer Institute. KDR Intron 2 VNTR. NCI Thesaurus. Code C129418.

A repetitive sequence found in intron 2 of the KDR gene. 